



\title{
da
}

\section{Documentación Administrativa}

Número 288: septiembre-diciembre 2010

\author{
Tribunales Administrativos \\ de Recursos Contractuales: \\ Central y Autonómicos
}

\section{INAP}



La Revista Documentación Administrativa es, dentro de las publicaciones periódicas de la especialidad, una referencia insoslayable en la construcción doctrinal del Derecho Administrativo y de la Ciencia de la Administración españolas. Nacida en 1958, acumula ya más de medio siglo de vida en el que su principal signo de identidad ha consistido en ser una publicación volcada a la reflexión, desde el derecho y las ciencias de la administración, sobre la reforma administrativa, la organización administrativa y la función pública. A partir del año 1987, la Revista inició una nueva etapa, que llega a nuestros días, caracterizada por la publicación exclusivamente de números de carácter monográfico. En ella, Documentación Administrativa se ha propuesto, llevada de la mano de su Consejo de Redacción, abordar temas carentes aún de reflexión doctrinal o en los que ésta es incipiente, así como abordar temas que, aun habiendo sido ya objeto de estudio, están reclamando nuevos enfoques o análisis de actualización y puesta día. Por otra parte, sin dejar de ser fiel a sus temas clásicos, en esta nueva etapa la Revista se ha propuesto asimismo reforzar los enfoques interdisciplinar y prospectivo sobre las cuestiones doctrinales generales y sectoriales que plantean los nuevos retos a los que se enfrenta la Administración Pública.

Con el objeto de seguir disfrutando el reconocimiento que la comunidad científica ha venido otorgando a la revista a lo largo de su ya dilatada vida, el INAP ha decidido la aplicación a Documentación Administrativa de los requisitos y exigencias de los sistemas más acreditados de calidad de las publicaciones periódicas de carácter científico y, entre ellos, la evaluación anónima por pares de los originales que se han de publicar.

Director del INAP: Manuel Arenilla Sáez

Director de la Revista: Luciano Parejo Alfonso (Catedrático de Derecho Administrativo-Universidad Carlos III)

\section{Consejo de Redacción}

Manuel Aragón Reyes (Catedrático de Derecho Constitucional. Universidad Autónoma de Madrid), José María Baño León (Catedrático de Derecho Administrativo. Universidad de Valencia), Martín Bassols Coma (Catedrático de Derecho Administrativo), Andrés de Blas Guerrero (Catedrático de Ciencia Política. UNED), José Manuel Castells Arteche (Catedrático de Derecho Administrativo. Universidad del País Vasco), Francisco González Navarro (Catedrático de Derecho Administrativo), Francisco López Menudo (Catedrático de Derecho Administrativo. Universidad de Sevilla), Julia Marchena Navarro (Cuerpo Superior de Administradores Civiles del Estado), David Mellado Ramírez (Secretario General Técnico. Ministerio de Hacienda y Administraciones Públicas) José Ramón Parada Vázquez (Catedrático de Derecho Administrativo), Álvaro Rodríguez Bereijo (Catedrático de Derecho Financiero y Tributario. Universidad Autónoma de Madrid), Juan Alfonso Santamaría Pastor (Catedrático de Derecho Administrativo. Universidad Complutense), Joaquín Tornos Mas (Catedrático de Derecho Administrativo. Universidad de Barcelona).

Secretario de Redacción: Jesús Prieto de Pedro (Catedrático de Derecho Administrativo. UNED) Vicesecretario de Redacción: Antonio Descalzo González (Universidad Carlos III de Madrid) 
DIRECTOR:

Luciano Parejo Alfonso

COORDINADOR:

Martín Bassols Coma

SECRETARIO DE LA REVISTA Y DEL CONSEJO DE REDACCIÓN:

Jesús Prieto de Pedro

VICESECRETARIO DE LA REVISTA:

Antonio Descalzo González

COORDINACIÓN:

Centro de Publicaciones del INAP

\section{CONSEJO DE REDACCIÓN}

\section{Presidente: Manuel Arenilla Sáez}

Vocales: Manuel Aragón Reyes, José María Baño León, Martín Bassols Coma, Andrés de Blas Guerrero, José Manuel Castells Arreche, Francisco González Navarro, Francisco López Menudo, Julia Marchena Navarro, David Mellado Ramírez, J. Ramón Parada Vázquez, Álvaro Rodríguez Bereijo, Juan Alfonso

Santamaría Pastor, Joaquín Tornos Mas

EDITA

Instituto Nacional de Administración Pública

NIP0: $635-12-005-5$ (formato papel)

635-12-004-X (formato electrónico)

ISSN: $0012-4494$ (formato papel)

1989-8983 (formato electrónico)

DEPÓSITO LEGAL: M-581-1958

Preimpresión: Lerko Print, S.A.

Impresión: Publidisa

\section{SUSCRIPCIONES Y VENTA}

Secretaría de la revista Documentación Administrativa

Centro de Publicaciones

Instituto Nacional de Administración Pública

Atocha, 106, 28012 Madrid

Tfno.: +34-912739104

www.inap.es

Catálogo general de publicaciones oficiales: http//www.060.es

\section{PRECIOS}

Suscripción anual 28,00 euros

Número sencillo $\quad 11,63$ euros

Número doble 23,25 euros

Incluidos IVA y gastos de envío

En esta publicación se ha utilizado papel reciclado libre de cloro de acuerdo con los criterios medioambientales de la contratación pública. 


\section{Sumario}

Página

I. CUESTIONES Presentación

GENERALES Coordinador: Martín Bassols Coma

13

El Tribunal Administrativo Central de Recursos

contractuales

The Public Procurement Review Central Administrative Court

19

J.J. Pardo García-Valdecasas

La normativa europea procesal de contratación

pública y sistema actual de recursos

contractuales

European Public procurement procedural legislation and the

current public procurement review system

Santiago González-Varas Ibáñez

Competencias y legitimación ante el Tribunal

Administrativo Central de Recursos Contractuales

(TACRECO): especial consideración de los

supuestos de nulidad contractual

Appearance and legitimation in the Public Procurement

65

Review Central Administrative Court: with particular regard to nullity of contract cases

Manuel Pulido Quecedo

La confidencialidad en la resolución del recurso especial en materia de contratación en el sector de la defensa y la seguridad pública y el Tribunal Administrativo Central de Recursos Contractuales Confidentiality in resolution of the special appeal for contracts in the sector of Defense and Public Security and the Administrative Central Court for Contractual Appeals Martín Bassols Coma 
Página
II. ÓRGANOS El Tribunal de Recursos contractuales
CONSTITUCIONALES $\begin{aligned} & \text { de las Cortes Generales } \\ & \text { The Public Procurement Court of the Spanish Parlament }\end{aligned}$ Luis de la Peña Rodríguez

131

\section{COMUNIDADES AUTÓNOMAS}

Tribunal Administrativo de Recursos

Contractuales de la Junta de Andalucía

The Public Procurement Review Court of the Autonomous

Region of Andalucia

Francisca Villalba Pérez

Notas sobre el Recurso Especial y su finalidad y las funciones del Tribunal Administrativo de Contratos Públicos de Aragón: su doctrina Notes of the special review and the functions of the Public Procurement Administrative Court of Aragón: its doctrine José María Gimeno Feliu

Órgano administrativo competente para conocer del recurso especial en materia de contratación pública en Castilla y León

The Special Public Procurement Review Authority of Castilla y León

José Carlos Laguna de Paz

El Órgano administrativo de Recursos

Contractuales de Cataluña: un nuevo avance en la garantía del derecho a una buena administración The Public Procurement Review Administrative Authority of Catalonia: another step towards guaranteeing the right to a Good Public Administration Juli Ponce Solé Oscar Capdeferro Villagrasa

El Órgano Administrativo de Recursos Contractuales de la Comunidad Autónoma de Euskadi y los órganos colegiados de los Territorios Históricos The Public Procurement Review Administrative Authority of the Autonomous Region of Euskadi and the collegiate bodies of the Historical Territories

Ramón Terol Gómez 
Página

Las reclamaciones en materia de contratación

pública en Navarra

Public procurement claims in Navarre

235

José Francisco Alenza García

El Tribunal de Contratación Pública de la

Comunidad de Madrid

The Public Procurement Court of the Autonomous Region of

259

Madrid

Alberto Palomar Olmeda

IV. DOCUMENTACIÓN Actividad del Tribunal Administrativo Central de Recursos Contractuales

Resolución de 28 de marzo de 2012, de la

Dirección General de Patrimonio del Estado, por

la que se publica la Recomendación de la Junta

Consultiva de Contratación Administrativa sobre

la interpretación del régimen contenido dentro

de la disposición transitoria séptima, norma d)

del Texto Refundido de la Ley de Contratos

del Sector Público (B.O.E. 10 de abril 2012)

Selección de Resoluciones de especial interés del Tribunal Central de Recursos Contractuales en el año 2012 
